\title{
Schröder, Bianca-Jeanette, Bildung und Briefe im 6. Jahrhundert. Studien zum Mailänder Diakon Magnus Felix Ennodius
}

\section{Stéphane Gioanni}

\section{OpenEdition}

\section{Journals}

Édition électronique

URL : http://journals.openedition.org/ifha/1658

DOI : 10.4000/ifha. 1658

ISSN : 2198-8943

Éditeur

IFRA - Institut franco-allemand (sciences historiques et sociales)

Référence électronique

Stéphane Gioanni, « Schröder, Bianca-Jeanette, Bildung und Briefe im 6. Jahrhundert. Studien zum Mailänder Diakon Magnus Felix Ennodius », Revue de I'IFHA [En ligne], Date de recension, mis en ligne le 01 janvier 2008, consulté le 22 septembre 2020. URL : http://journals.openedition.org/ifha/1658 ; DOI : https://doi.org/10.4000/ifha.1658

Ce document a été généré automatiquement le 22 septembre 2020.

(CIFHA 


\title{
Schröder, Bianca-Jeanette, Bildung und Briefe im 6. Jahrhundert. Studien zum Mailänder Diakon Magnus Felix Ennodius
}

\author{
Stéphane Gioanni
}

La publication de la thèse d'habilitation de B.-J.S. s'inscrit dans le renouveau des études ennodiennes initié par Christian Rohr (Der Theoderich-Panegyricus des Ennodius, Hannover, 1995) et poursuivi par l'organisation régulière des Giornate Ennodiane à Pavie et à Naples en 2000, 2001 et 2004. Le premier mérite de ce nouvel ouvrage est de faire le point sur les recherches en cours et sur une bibliographie de plus en plus fournie. La première partie (Cultura sermonis, $\mathrm{p}$ 11-135) apporte de précieux compléments à la monographie de Stefanie A. H. Kennell (Magnus Felix Ennodius, Ann Arbor, 2000) sur la vie et les œuvres d'Ennode qui seraient, selon la tradition, contemporaines de son diaconat à Milan et donc antérieures à son épiscopat à Pavie. L'analyse méthodique des œuvres (p 31-53), y compris des Hymnes souvent négligées, rendra le plus grand service au lecteur de cet auteur « difficilis et obscurus » dont la réception a beaucoup souffert des critiques acerbes de l'évêque Arnulf de Lisieux au XIIe s. La biographie d'Ennode offre, quant à elle, un parfait exemple de l'attitude ambiguë des clercs à l'égard de la culture profane que le diacre de Milan condamne et cultive à la fois (cf. ses carmina et ses dictiones). Le niveau stylistique de ses productions et ses préoccupations pédagogiques montrent la persistance, dans les cercles du pouvoir, d'une culture de l'écrit et la volonté d'entretenir l'excellence culturelle des anciennes élites impériales. Par cette démonstration (connue mais essentielle), la première partie constitue une utile introduction à la lecture d'Ennode et des auteurs contemporains qui appartiennent tous à l'aristocratie gallo-romaine (Avit de Vienne, Cassiodore, Boèce...). Elle permet aussi d'évaluer le niveau de la production littéraire et l'évolution de la culture chrétienne sous le règne de Théodoric un quart de siècle après la chute de l'Empire romain d'Occident. L'auteur peut alors se concentrer, dans la seconde partie (Testimonium diligentiae, p. 136-372), sur la Correspondance 
d'Ennode qui constitue un témoignage exceptionnel sur le genre épistolaire de langue latine au début du VIe s. mais aussi sur la société de l'Italie ostrogothique. Le projet était ambitieux et la matière abondante (297 lettres réparties en 9 livres). L'auteur propose une analyse strictement littéraire qui parvient à montrer les caractéristiques des lettres d'Ennode ( $\mathrm{p}$ 166-284) : celles-ci s'inscrivent dans la tradition de l'épistolographie antique (p 136-165 : études des topoi, des officia, etc.) tout en contribuant à son renouvellement, comme le montrent l'écriture abstraite et métaphorique (Kanzleistil), le rôle croissant des praefationes qui délivrent une représentation idéale de l'échange épistolaire ( $\mathrm{p}$ 258-259) ou sa conception originale de l'amicitia épistolaire sur laquelle B.-J.S. insiste fortement (p 285 suiv.). Les spécialistes des correspondances apprécieront aussi l'effort de typologie des lettres (p 147-150: : Zur Kategorisierung von Briefen ») qui relève néanmoins de l'interprétation compte tenu de l'hermétisme et du caractère allusif de l'écriture d'Ennode.

2 Si l'interprétation de tel ou tel détail peut sembler discutable (par exemple sur Speciosa, l'ancienne « fiancée » d'Ennode, p 273), l'étude littéraire proposée par B.-J.S. apporte une contribution importante aux études sur le genre épistolaire de l'Antiquité tardive. Nos principales réserves sont d'ordre méthodologique. Tout d'abord, même si les lettres d'Ennode sont à l'évidence des textes littéraires, il n'en est pas moins vrai, comme le reconnaît B.-J.S., qu'elles demeurent de véritables missives et qu'elles constituent un mode de communication à part entière. Dès lors, l'étude des epistulae ne saurait faire l'économie d'une étude même élémentaire des correspondants et du milieu dans lequel ces lettres ont été écrites et transmises : qui sont ces destinataires? Où se trouvent-ils ? Quelle est leur fonction? Quelles relations existent entre eux (amitié, parenté, clientélisme) ? La focalisation sur certains personnages exemplaires (recusationes, $\mathrm{p}$ 178-196) ne saurait pénétrer la complexité des réseaux en présence (entre Milan, Rome et Ravenne), ni la compétition entre les élites aristocratiques, cléricales et courtisanes auxquelles les lettres d'Ennode offrent l'un des rares moyens d'expression. L'extrême complexité du style constitue elle-même une stratégie de distinction et de communication qui excluait sans doute une bonne partie des élites gothiques et qui montre que la littérature n'est jamais très loin de l'histoire.

3 La seconde remarque porte sur l'implication d'Ennode à la chancellerie pontificale de Symmaque et d'Hormisdas. L'auteur considère qu'il n'en est pas question dans ses lettres (p. 26) ! Nous sommes en désaccord avec cette interprétation. Peut-on imaginer, en effet, que les lettres d'Ennode aux principaux acteurs du schisme laurentien soient indifférentes au conflit, alors qu'Ennode est choisi par le pape au même moment pour prononcer sa défense en plein concile (opusc. II : Libellus pro Synodo) ? De nombreux indices peuvent être interprétés, dans les lettres, comme des allusions ou des souvenirs du schisme : l'évocation d'un " mal sous lequel Rome agonise " (epist. 1, 3), les « accusations portées contre le pape » (epist. 5, 13), les épîtres relatives à la succession de l'évêque d'Aquilée qui s'était montré hostile au pape durant le schisme (epist. 4, $1 ; 4,29$ $; 5,1)$, l'éloge du roi Théodoric qui a permis la victoire de Symmaque (epist. 9, 30), etc. En outre, la présence, dans la Correspondance d'Ennode, de lettres attribuées à des papes dans les collections pontificales (epist. 2, 14 et epist. 5, 1) devrait au moins attirer l'attention sur le rôle des épîtres d'Ennode dans ces crises où se joue un chapitre majeur de l'histoire pontificale : Ennode ne fut-il pas choisi par le pape pendant le schisme acacien pour conduire les ambassades pontificales en Orient et pour rédiger les épîtres pontificales destinées à la pars Orientis ? Son engagement aux côtés du pape ne 
fut-il pas célébré au XIe s. dans les dictatus pape de Grégoire VII ? Des chercheurs ont même considéré que l'absence de lettres à certains ennemis du pape pouvait constituer des indices probants de son engagement auprès du pape Symmaque (E. Wirbelauer, Zwei Päpste in Rom. Der Konflikt zwischen Laurentius und Symmachus (498-514), München, 1993, p. 60-61). Dès lors, l'absence d'allusion explicite aux schismes dans la Correspondance ne doit pas être prise au pied de la lettre. Elle s'explique par l'exigence littéraire des épîtres et par l'habitude de confier aux porteurs les messages brûlants. L'apparente vacuité des lettres et l'ambiguïté de l'écriture épistolaire d'Ennode définissent un mode d'écriture politique qui suscita l'intérêt des chancelleries et des écoles médiévales comme le prouvent les nombreuses citations d'épîtres ennodiennes dans les florilèges d'ars dictaminis à partir du XIIe $s$.

De façon générale, on peut s'étonner que B.-J.S. n'ait consacré que cinq lignes à la transmission manuscrite d'Ennode (p. 28). Sa réception a pourtant beaucoup varié en fonction des aléas de sa transmission. Après avoir été célébré par les papes Nicolas Ier et Grégoire VII comme l'un des principaux hérauts de la primauté pontificale, Ennode fut essentiellement copié pour son style épistolaire qui, avec d'autres correspondances tardo-antiques, fut considéré comme un modèle pour la rhétorique de chancellerie. L'étude des manuscrits a permis également de s'interroger sur l'origine de la collection ennodienne et sur le classement interne des œuvres, longtemps considéré comme chronologique. Le moins que l'on puisse dire est que ce classement pose de nombreux problèmes. En l'absence de repères chronologiques explicites (les exceptions sont très rares comme le constate l'éditeur F. Vogel, dans Opera Ennodii, Berlin, 1885, MGH, AA, 7, p. XXVIII), les rapprochements entre les textes sont souvent hypothétiques. Dès lors, de nombreuses contradictions d'Ennode (notamment sur la culture profane : cf. epist. 9, 1 à Arator // carm. 1, 5 Itinerarium) ne pourraient-elles pas s'expliquer par les rapprochements hasardeux d'un collecteur qui ignorait en grande partie la chronologie de ses œuvres ? On peut regretter que B.-J.S., qui avait une vue d'ensemble de la Correspondance, n'ait pas dit un seul mot sur l'origine et l'organisation interne de cette collection. En effet, les épîtres recèlent de précieux indices sur l'évolution des rapports entre les correspondants qui montrent les " erreurs de classement » du collecteur et qui confortent l'idée d'une collection tardive, peut-être contemporaine de la redécouverte des œuvres par Paul Diacre à la fin du VIIIe s. En tout cas, on ne peut pas exclure cette hypothèse qui est confortée par de nombreux éléments (cf. « Nouvelles hypothèses sur la datation de la collection d'Ennode » in : Atti della III Giornata Ennodiana, F. Gasti (dir.), Pavia, 2006, p 59-76). Cette question est d'autant plus importante qu'elle remettrait en cause l'interprétation traditionnelle selon laquelle aucune œuvre conservée d'Ennode n'a été écrite après son accession au siège de Pavie. Si la chronologie est à revoir, un certain nombre de lettres pourraient avoir été écrites non pas par le diacre de Milan mais par l'évêque de Pavie (dont ne tient pas du tout compte B.-J.S.).

5 En conclusion, nous redisons que l'étude d'une correspondance ne peut négliger le milieu dans lequel ses lettres ont été échangées ni la tradition manuscrite qui les a transmises jusqu'à nous. Mais ces remarques n'enlèvent rien à l'intérêt de ce livre qui propose de nombreuses interprétations sur des lettres dont personne ne saurait prétendre détenir les clefs. Nous espérons à présent que ce commentaire sera complété bientôt par la traduction des lettres d'Ennode qui permettrait à tous d'accéder à cette 
œuvre difficile mais fondamentale pour l'étude de l'Italie théodoricienne et de la littérature épistolaire au VIe s.

6 Stéphane Gioanni (Université de Paris I - Panthéon-Sorbonne) 